Pacific Journal of Mathematics

SEQUENCE TRANSFORMATIONS THAT GUARANTEE 


\title{
SEQUENCE TRANSFORMATIONS THAT GUARANTEE A GIVEN RATE OF CONVERGENCE
}

\author{
G. H. Fricke AND J. A. Fridy
}

Let $t$ be a positive number sequence and define the sequence space $\Omega(t):=\left\{x: x_{k}=O\left(t_{k}\right)\right\}$. Characterizations are given for matrices that map the spaces $l^{1}, l^{\infty}, c$, or $c_{0}$ into $\Omega(t)$, thus ensuring that the transformed sequence converges at least as fast as $t$. These results yield information about matrices that map $l^{1}, l^{\infty}, c$, or $c_{0}$ into $G:=\bigcup_{r \in(0,1)} \Omega\left(r^{n}\right)$, the set of geometrically dominated sequences.

1. Introduction. For each $r$ in the interval $(0,1)$ let

$$
G(r)=\left\{\text { complex sequences } x: x_{k}=O\left(r^{k}\right)\right\}
$$

and define the set of geometrically dominated sequences as

$$
G=\bigcup_{r \in(0,1)} G(r) .
$$

The analytic sequences are defined by

$$
\mathscr{A}=\left\{\text { complex sequences } x: \limsup _{n}\left|x_{n}\right|^{1 / n}<\infty\right\} .
$$

Obviously $G \subseteq \mathscr{A}$. In $[2,6,9,10]$ the various authors studied matrix transformations from $\mathscr{A}$ or $G$ into $l^{1}, c$, or $l^{\infty}$, but the question of mapping from $l^{1}, c$, or $l^{\infty}$ into $\mathscr{A}$ or $G$ was not considered. We shall use the customary notation for a matrix transformation: if $A$ is an infinite matrix with complex entries and $x$ is a complex number sequence, then $A$ transforms $x$ into the sequence $A x$ whose $n$th term is given by

$$
(A x)_{n}=\sum_{k=0}^{\infty} a_{n k} x_{k} .
$$

The present work began as a study of $l^{1}-G$ and $c-G$ matrices, but it was found that such results are merely special cases of a more general theory. To set the stage for the general theory we replace the geometric sequence $\left\{r^{k}\right\}$ with a nonnegative sequence $t$ and define

$$
\Omega(t)=\left\{x: x_{k}=O\left(t_{k}\right)\right\} .
$$


Throughout the paper $T$ will denote a sequence $\left\{t^{(m)}\right\}_{n=1}^{\infty}$ of nonnegative number sequences such that $t^{(m)} \in \Omega\left(t^{(m+1)}\right)$ for each $m$; this ensures that $\Omega\left(t^{(m)}\right) \subseteq \Omega\left(t^{(m+1)}\right)$, and we define

$$
D(T)=\bigcup_{m=0}^{\infty} \Omega\left(t^{(m)}\right) \text {. }
$$

EXAMPLE 1. If for each $m, t^{(m)}$ is the geometric sequence $\left\{r_{m}^{k}\right\}$, where $0<r_{m}<1$ and $r_{m} \uparrow 1$, then $D(T)$ is $G$.

For a given summability matrix $A$, the sequences $\mu$ and $\sigma$ are defined by

$$
\mu_{n}=\sup _{k}\left|a_{n k}\right|
$$

and

$$
\sigma_{n}=\sum_{k=0}^{\infty}\left|a_{n k}\right| .
$$

The main results of this paper state that for $A$ to map $l^{1}$ [respectively, $c$ ] into a "big-oh space" such as $\Omega(t)$, it is necessary and sufficient that $\mu$ be in $\Omega(t)$ [respectively, $\sigma \in \Omega(t)$ ]. Moreover, in order for $A$ to map $l^{1}$ [respectively, $c$ ] into $D(T)$ it is necessary that $A$ map into a particular $\Omega\left(t^{(m)}\right)$ for some $t^{(m)}$ in $T$. Thus the characterizations of $A: l^{1} \rightarrow G$ and $A: c \rightarrow G$ are obtained as special cases of the general theory.

The final section of the paper contains a brief discussion of some classical matrix methods as mappings into $\Omega(t)$ spaces.

2. The main results. Using the notation as given above, we proceed to our first general result.

THEOREM 1. If $A$ is a summability matrix and $T, D(T)$, and $\mu$ are as given above, then the following are equivalent:

(i) $\mu \in D(T)$;

(ii) there exists a $t^{(m)}$ in $T$ such that $\mu \in \Omega\left(t^{(m)}\right)$;

(iii) there exists a $t^{(m)}$ in $T$ such that $A: l^{1} \rightarrow \Omega\left(t^{(m)}\right)$;

(iv) $A: l^{1} \rightarrow D(T)$.

Proof. Implications (i) $\Rightarrow$ (ii) $\Rightarrow$ (iii) $\Rightarrow$ (iv) are obvious. To prove that (iv) $\Rightarrow(\mathrm{i})$, first note that (iv) implies that

$$
\mu_{n}<\infty \text { for each } n
$$

and

$$
\text { each column of } A \text { is in } D(T) \text {. }
$$


It follows from (2) that the sum of any finite number of columns of $A$ is in $D(T)$, so there exists a sequence $\left\{t^{\left(m^{*}\right)}\right\}$ in $T$ and a positive number sequence $\left\{B_{m^{*}}\right\}$ that increases to $\infty$ such that

$$
\sum_{i \leq m^{*}}\left|a_{n i}\right| \leq B_{m^{*}} t_{n}^{\left(m^{*}\right)} \text { for each } n \text {. }
$$

To simplify the notation we will write $m$ in place of $m^{*}$ since the nestedness of the sets $\left\{\Omega\left(t^{(m)}\right)\right\}$ ensures that nothing is lost by considering the subsequence $\left\{t^{\left(m^{*}\right)}\right\}$ as the entire sequence $\left\{t^{(m)}\right\}$.

Now assume (1), (2), and (3) hold, but $\mu \notin D(T)$; we wish to construct an $x$ in $l^{1}$ such that $A x \notin D(T)$. From each row of $A$ select an entry satisfying

$$
\left|a_{n, k^{*}(m)}\right| \geq \frac{1}{2} \mu_{n} \text {. }
$$

Since $\mu \notin D(T),(2)$ allows us to choose a subsequence of these entries, say $\left\{a_{n^{\prime}(i), k^{\prime}(i)}\right\}_{k=1}^{\infty}$ such that $n^{\prime}(i)$ and $k^{\prime}(i)$ increase with $i$; also, $\mu \notin D(T)$ allows us to choose the $n^{\prime}(i)$ so that

$$
\sup _{i}\left\{\mu_{n^{\prime}(i)} / t_{n^{\prime}(i)}^{(m)}\right\}=\infty \text { for all } m \text {. }
$$

For each $i$ we also have

$$
\left|a_{n^{\prime}(i), k^{\prime}(i)}\right| \geq \frac{1}{2} \mu_{n^{\prime}(i)}=\frac{1}{2} \sup _{k}\left\{\left|a_{n^{\prime}(i), k}\right|\right\} .
$$

Finally, choose a further subsequence of these entries so that for each $j$

$$
\left|a_{n(j), k(j)}\right|>12 B_{k(j-1)} t_{n(j)}^{(k(j-1))} 4^{j} .
$$

Now define $x$ in $l^{1}$ by

$$
x_{k}=\left\{\begin{array}{ll}
4^{-j}, & \text { if } k=k(j) \\
0, & \text { otherwise. }
\end{array} \text { and } a_{n(j), k(j)} \neq 0,\right.
$$

For each $j$ this yields

$$
\begin{aligned}
\left|(A x)_{n(j)}\right| & \geq-\sum_{i<j}\left|a_{n(j), k(i)}\right| 4^{-i}+\left|a_{n(j), k(j)}\right| 4^{-j}+\sum_{i>j}\left|a_{n(j), k(i)}\right| 4^{-i} \\
& \geq-B_{k(j-1)} t_{n(j)}^{(k(j-1))}+\frac{1}{2} \mu_{n(j)} 4^{-j}-\mu_{n(j)} \sum_{i>j} 4^{-j} \\
& \geq-B_{k(j-1)} t_{n(j)}^{(k(j-1))}+\frac{1}{6} \mu_{n(j)} 4^{-j} \\
& >-B_{k(j-1)} t_{n(j)}^{(k(j-1))}+\frac{1}{6}\left[12 B_{k(j-1)} t_{n(j)}^{(k(j-1))} 4^{j}\right] 4^{-j} \\
& =B_{k(j-1)} t_{n(j)}^{(k(j-1))} .
\end{aligned}
$$


Hence, $A x \notin \Omega\left(t^{(k(j-1))}\right)$, and it follows that $A x \notin D(T)$.

By taking $T$ as in Example 1 we get the following corollary as an immediate consequence of Theorem 1 .

COROLlaRy 1A. If $A$ is a summability matrix and $\mu_{n}=\sup _{k}\left|a_{n k}\right|$, then $A: l^{1} \rightarrow G$ if and only if $\mu \in G$.

Another consequence of Theorem 1 can be obtained by replacing $T$ with a single sequence, i.e., $t^{(m)}=t$ for every $m$. Thus $D(T)=\Omega(t)$, and we get the following result.

COROllary 1B. If $A$ is a summability matrix and $t$ is a nonnegative number sequence, then $A=l^{1} \rightarrow \Omega(t)$ if and only if $\mu \in \Omega(t)$.

This corollary gives rise to the title of the paper, because it characterizes those matrices $A$ that will transform every absolutely convergent series $\sum x_{k}$ into a series $\sum(A x)_{n}$ that converges at least as fast as a given series $\sum t_{n}$.

Now we turn our attention to matrix mappings from $l^{\infty}$ into $D(T)$, which, as we shall see, subsumes the cases of mappings from $c$ or $c_{0}$ into $D(T)$.

THEOREM 2. If $A$ is a summability matrix and $T, D(T)$, and $\sigma$ are as given above, then the following are equivalent:

(i) $\sigma \in \mathcal{E}(T)$;

(ii) there exists a $t^{(m)}$ in $T$ such that $\sigma \in \Omega\left(t^{(m)}\right)$;

(iii) there exists a $t^{(m)}$ in $T$ such that $A: l^{\infty} \rightarrow \Omega\left(t^{(m)}\right)$;

(iv) there exists a $t^{(m)}$ in $T$ such that $A: c \rightarrow \Omega\left(t^{(m)}\right)$;

(v) there exists a $t^{(m)}$ in $T$ such that $A: c_{0} \rightarrow \Omega\left(t^{(m)}\right)$;

(vi) $A: c_{0} \rightarrow D(T)$.

Proof. As in the proof of Theorem 1, most of the implications are obvious and we prove here only that (vi) $\Rightarrow(\mathrm{i})$. Note that (vi) implies that each row of $A$ is in $l^{1}$ (i.e., $\sigma_{n}<\infty$ ) and each column of $A$ is in some $\Omega\left(t^{(m)}\right)$. Therefore finite sums of the column sequences are in $D(T)$, and we can choose a sequence of $t^{(j)}$ 's with constants $B_{j}>0$ such that for each $j$

$$
\sum_{k \leq j}\left|a_{n k}\right| \leq B_{j} t_{n}^{(j)}
$$

Suppose that $\sigma \notin D(T)$. Choose increasing sequences $\{k(j)\}$ and $\{n(j)\}$ of column and row indices as follows: $k(1)$ and $n(0)$ are 
chosen arbitrarily, and after $k(j)$ and $n(j-1)$ are selected choose $n(j)>n(j-1)$ so that

$$
\sigma_{n(j)} \geq\left[j\left(2 B_{k(j)}+j\right)+2 B_{k(j)}\right] t_{n(j)}^{(k(j))} .
$$

Next choose $k(j+1)>k(j)$ so that

$$
\sum_{k>k(j+1)}\left|a_{n(j), k}\right|<B_{k(j)} t_{n(j)}^{(k(j))} .
$$

Thus (7), (8), and (9) together yield

$$
\sum_{k=1+k(j)}^{k(j+1)}\left|a_{n(j), k}\right| \geq j\left(2 B_{k(j)}+j\right) t_{n(j)}^{(k(j))} .
$$

Now define the sequence $x$ by

$$
x_{k}=\frac{\bar{a}_{n(j), k}}{\left|a_{n(j), k}\right| j}, \quad \text { if } k(j)<k \leq k(j+1) \text { and } a_{n(j), k} \neq 0,
$$

and $x_{k}=0$ otherwise. It is clear that $x \in c_{0}$, but for each $j$ we have

$$
\begin{aligned}
\left|(A x)_{n(j)}\right| & \geq-\sum_{k \leq k(j)}\left|a_{n(j), k}\right|+\left|\sum_{k=1+k(j)}^{k(j+1)} a_{n(j), k} x_{k}\right|-\sum_{k>k(j+1)}\left|a_{n(j), k}\right| \\
& \geq-2 B_{k(j)} t_{n(j)}^{(k(j))}+\sum_{k=1+k(j)}^{k(j+1)}\left|a_{n(j), k}\right| \frac{1}{j} \geq j t_{n(j)}^{(k(j))} .
\end{aligned}
$$

Hence, $A x \notin \Omega\left(t^{(k(j))}\right)$ for $j=1,2, \ldots$, so $A x \notin D(T)$. Thus we have shown that if (i) is false then (vi) does not hold, which completes the proof.

As with Theorem 1, we can state two immediate corollaries to Theorem 2. The first is the case in which $D(T)=G$ as in Example 1, and the second is the case in which $T$ consists of a single sequence.

COROLlaRY 2A. If $A$ is a summability matrix and $\sigma_{n}=\sum_{k=1}^{n}\left|a_{n k}\right|$, then $A$ maps $l^{\infty}, c$, and $c_{0}$ into $G$ if and only if $\sigma \in G$.

COROllary 2B. If $A$ is a summability matrix and $t$ is a nonnegative number sequence, then $A$ maps $l^{\infty}, c$, and $c_{0}$ into $\Omega(t)$ if and only if $\sigma \in \Omega(t)$.

Once again, it is the latter corollary that is described in the title of the paper: for, if one wishes to have a matrix $A$ that transforms 
every null sequence into a sequence that converges at least as rapidly as some $t_{n} \downarrow 0$, then $A$ must satisfy $\sigma \in \Omega(t)$. Similarly, if $t$ is a nonzero constant sequence, then $\Omega(t)=l^{\infty}$, and in this case Corollary $2 \mathrm{~B}$ reduces to the well-known result that $A$ preserves boundedness if and only if $\sigma$ is bounded.

Another observation should be made about obtaining a "given rate of convergence" by mapping $c_{0}$ into $\Omega(t)$. Recent work [1, 7] has shown that regular matrices cannot accelerate the rate of convergence of every null sequence. Therefore, we emphasize that having $A$ map $c_{0}$ into $\Omega(t)$ does not say that every sequence in $c_{0}$ is accelerated, even if $t_{n} \downarrow 0$ very rapidly; some sequences that are already in $\Omega(t)$ may map into other members of $\Omega(t)$ that converge at the same rate or slower.

3. Examples involving classical matrices. If $A$ is regular then $\sigma \in$ $l^{\infty}$ but $\sigma \notin c_{0}$. Therefore Theorem 2 and its corollaries do not yield much information about regular matrices, and this includes most of the classical methods. We can, however, draw some conclusions about mapping $l^{1}$ into $\Omega(t)$ by finding $\mu$ and applying Corollary $1 \mathrm{~B}$.

EXAMPLE 2. The Cesàro matrix of order $j$ is given by

$$
C_{j}[n, k]=\frac{\left(\begin{array}{c}
n+j-1-k \\
j-1
\end{array}\right)}{\left(\begin{array}{c}
n+j \\
j
\end{array}\right)}
$$

(see, e.g., [8, p. 46], so it is plain that

$$
\mu_{n}=C_{j}[n, 0]=\frac{j}{n+j},
$$

whence $C_{j}: l^{1} \rightarrow \Omega(1 / n)$.

EXAMPLE 3. For the Euler-Knopp mean of order $r$ it is known [3, Theorem 9] that $\mu_{n} \sim[2 \pi r(1-r) n]^{-1 / 2}$; so by Corollary 1B, $E_{r}: l^{1} \rightarrow \Omega\left(n^{-1 / 2}\right)$.

EXAMPLE 4. For the Taylor matrix $T_{r}$ [3, Theorem 11] we have $\mu_{n} \sim(1-r)[2 \pi r n]^{-1 / 2}$, and therefore

$$
T_{r}: l^{1} \rightarrow \Omega\left(n^{-1 / 2}\right)
$$

EXAMPle 5. The Borel matrix $[8$, p. 53] is given by $B[n, k]=$ $e^{-n} n^{k} / k$ !, and it is not hard to show that

$$
\mu_{n}=B[n, n]=\left(\frac{n}{e}\right)^{n} \frac{1}{n !} .
$$


From Stirling's Formula it follows that

$$
\mu_{n} \sim \frac{1}{\sqrt{r \pi n}}
$$

and so $B$, like $E_{r}$ and $T_{r}$, maps $l^{1}$ into $\Omega\left(n^{-1 / 2}\right)$.

EXAMPle 6. The Hausdorff means [5, Chapter 5] can be defined by

$$
H_{\varphi}[n, k]=\int_{0}^{1} E_{r}[n, k] d \varphi,
$$

where $E_{r}$ is the Euler-Knopp mean and $\int_{0}^{1}|d \varphi|<\infty$. Thus from Example 3 we infer that

$$
\left|H_{\varphi}[n, k]\right| \leq K n^{-1 / 2} \int_{0+}^{1-}[r(1-r)]^{-1 / 2}|d \varphi(r)|,
$$

where $K$ is a constant. Therefore we conclude that if

$$
\int_{0+}^{1-}[r(1-r)]^{-1 / 2}|d \varphi|<\infty
$$

then $\mu_{n}=O\left(n^{-1 / 2}\right)$ and $H_{\varphi}: l^{1} \rightarrow \Omega\left(n^{-1 / 2}\right)$.

ExAMPLE 7. The Nörlund mean generated by the nonnegative sequence $p$ with $p_{0}>0$ is given by

$$
N_{p}[n, k]= \begin{cases}p_{n-k} / P_{n}, & \text { if } k \leq n, \\ 0, & \text { if } k>n .\end{cases}
$$

In general,

$$
\mu_{n}=\frac{1}{P_{n}} \max \left\{p_{k}\right\}_{k=0}^{n},
$$

and this is somewhat awkward in Corollary 1B. In case $p$ is monotonic the $\mu$ formula becomes quite simple, and we can state the following easy conclusions:

(i) if $p$ is nonincreasing, then $\mu_{n}=p_{0} / P_{n}$ and $N_{p}: l^{1} \rightarrow \Omega\left(1 / P_{n}\right)$;

(ii) if $p$ is nondecreasing then $\mu_{n}=p_{n} / P_{n}$ and $N_{p}=l^{1} \rightarrow$ $\Omega\left(p_{n} / P_{n}\right)$.

It should be noted that these results do not always give much information. For example, in Case (i) if $p \in l^{1}$ then $1 / P \notin c_{0}$ and (i) asserts only that $N_{p}$ maps $l^{1}$ into $l^{\infty}$. (Every Nörlund matrix maps $l^{\infty}$ into $l^{\infty}$ because $\sigma_{n}:=1$.) Similarly, if $p_{n}=R^{n}$, where $R>1$, then $p_{n} / P_{n} \sim(R-1) / R$, and (ii) tells us only that $N_{p}$ maps $l^{1}$ into $l^{\infty}$. 
EXAmple 8. An Abel matrix [4] is given by

$$
A_{t}[n, k]=t_{n}\left(1-t_{n}\right)^{k}
$$

where $0<t_{n}<1$ and $\lim _{n} t_{n}=0$. For $A_{t}$ it is obvious that $\mu_{n}=t_{n}$, and therefore by Corollary $1 \mathrm{~B}, A_{t}: l^{1} \rightarrow \Omega(t)$.

The authors would like to thank Professor James DeFranza for some very helpful conversations.

\section{REFERENCES}

[1] J. P. Delahaye and B. Germain-Bonne, The set of logarithmically convergent sequences cannot be accelerated, SIAM J. Numer. Anal., 19 (1982), 840-844.

[2] G. H. Fricke and J. A. Fridy, Matrix summability of geometrically dominated series, Canad. J. Math., 39 (1987), 568-582.

[3] J. A. Fridy, Matrix summability and a generalized Gibbs phenomenon, Aequat. Math., 14 (1976), 405-412.

[4] - Abel transformations into $l^{1}$, Canad. Math. Bull., 25 (1982), 421-427.

[5] G. H. Hardy, Divergent Series, Clarendon Press, Oxford, 1949.

[6] R. T. Jacob, Jr., Matrix transformations involving simple sequence spaces, Pacific J. Math., 70 (1977), 179-187.

[7] T. A. Keagy and W. F. Ford, Acceleration by subsequence transformations, Pacific J. Math., 132 (1988), 357-362.

[8] R. E. Powell and S. M. Shah, Summability Theory and Applications, Revised Ed., Prentice Hall of India, New Delhi, 1988.

[9] P. C. Tonne, Matrix transformations on the power-series convergent on the unit disc, J. London Math. Soc. (2), 4 (1972), 667-670.

[10] __ Matrix representations for linear transformations on series analytic in the unit disc, Pacific J. Math., 44 (1973), 385-392.

Received March 20, 1989.

Wright State University

DAYTON, OH 45435

AND

Kent State University

KENT, OH 44242 


\section{PACIFIC JOURNAL OF MATHEMATICS EDITORS}

\author{
V. S. VARADARAJAN \\ (Managing Editor) \\ University of California \\ Los Angeles, CA 90024-1555-05 \\ Herbert Clemens \\ University of Utah \\ Salt Lake City, UT 84112 \\ Thomas EnRIght \\ University of California, San Diego \\ La Jolla, CA 92093
}

R. FINN

Stanford University

Stanford, CA 94305

HeRmanN FlaschKa

University of Arizona

Tucson, AZ 85721

VAughan F. R. Jones

University of California

Berkeley, CA 94720

Steven Kerckhoff

Stanford University

Stanford, CA 94305

\section{C. Moore}

University of California

Berkeley, CA 94720

Martin ScharlemanN

University of California

Santa Barbara, CA 93106

Harold Stark

University of California, San Diego

La Jolla, CA 92093

\section{ASSOCIATE EDITORS}
R. ARENS
E. F. BECKENBACH
B. H. NEUMANN
F. WoLF
K. YoshidA (1906-1982)
(1904-1989)

\section{SUPPORTING INSTITUTIONS}

UNIVERSITY OF ARIZONA
UNIVERSITY OF BRITISH COLUMBIA
CALIFORNIA INSTITUTE OF TECHNOLOGY
UNIVERSITY OF CALIFORNIA
MONTANA STATE UNIVERSITY
UNIVERSITY OF NEVADA, RENO
NEW MEXICO STATE UNIVERSITY
OREGON STATE UNIVERSITY

\author{
UNIVERSITY OF OREGON \\ UNIVERSITY OF SOUTHERN CALIFORNIA \\ STANFORD UNIVERSITY \\ UNIVERSITY OF HAWAII \\ UNIVERSITY OF TOKYO \\ UNIVERSITY OF UTAH \\ WASHINGTON STATE UNIVERSITY \\ UNIVERSITY OF WASHINGTON
}

The Supporting Institutions listed above contribute to the cost of publication of this Journal, but they are not owners or publishers and have no responsibility for its content or policies.

Mathematical papers intended for publication in the Pacific Journal of Mathematics should be in typed form or offset-reproduced (not dittoed), double spaced with large margins. Please do not use built up fractions in the text of the manuscript. However, you may use them in the displayed equations. Underline Greek letters in red, German in green, and script in blue. The first paragraph must be capable of being used separately as a synopsis of the entire paper. In particular it should contain no bibliographic references. Please propose a heading for the odd numbered pages of less than 35 characters. Manuscripts, in triplicate, may be sent to any one of the editors. Please classify according to the 1980 Mathematics Subject Classification (1985 Revision) scheme which can be found in the December index volumes of Mathematical Reviews. Supply name and address of author to whom proofs should be sent. All other communications should be addressed to the managing editor, or Elaine Barth, University of California, Los Angeles, California 90024-1555-05.

There are page-charges associated with articles appearing in the Pacific Journal of Mathematics. These charges are expected to be paid by the author's University, Government Agency or Company. If the author or authors do not have access to such Institutional support these charges are waived. Single authors will receive 50 free reprints; joint authors will receive a total of 100 free reprints. Additional copies may be obtained at cost in multiples of 50 .

The Pacific Journal of Mathematics (ISSN 0030-8730) is published monthly. Regular subscription rate: $\$ 190.00$ a year (12 issues). Special rate: $\$ 95.00$ a year to individual members of supporting institutions.

Subscriptions, orders for numbers issued in the last three calendar years, and changes of address should be sent to Pacific Journal of Mathematics, P.O. Box 969, Carmel Valley, CA 93924, U.S.A. Old back numbers obtainable from Kraus Periodicals Co., Route 100, Millwood, NY 10546.

The Pacific Journal of Mathematics at P.O. Box 969, Carmel Valley, CA 93924 (ISSN 0030-8730) is published monthly. Second-class postage paid at Carmel Valley, California 93924, and additional mailing offices. Postmaster: send address changes to Pacific Journal of Mathematics, P.O. Box 969, Carmel Valley, CA 93924.

PUBLISHED BY PACIFIC JOURNAL OF MATHEMATICS, A NON-PROFIT CORPORATION

Copyright (C) 1990 by Pacific Journal of Mathematics 


\section{Pacific Journal of Mathematics}

\section{Vol. 146, No. 2 December, 1990}

David Fenimore Anderson, David Earl Dobbs, Paul M. Eakin, Jr. and

William James Heinzer, On the generalized principal ideal theorem and Krull domains .................................... 201

Richard C. Bradley, On $\rho$-mixing except on small sets $\ldots \ldots \ldots \ldots \ldots 217$

David H. Collingwood and Brad Shelton, A duality theorem for extensions

of induced highest weight modules $\ldots \ldots \ldots \ldots \ldots \ldots \ldots \ldots \ldots \ldots 27$

Gerd H. Fricke and John Albert Fridy, Sequence transformations that guarantee a given rate of convergence $\ldots . \ldots \ldots \ldots \ldots \ldots \ldots . \ldots . \ldots . \ldots 239$

Michael Justin Heumos and Stephen James Rallis, Symplectic-Whittaker

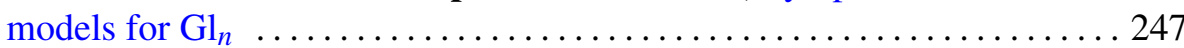

Severino Toscano do Rego Melo, A comparison algebra on a cylinder with

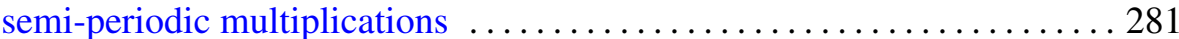

Daniel Pecker, On the elimination of algebraic inequalities ........... 305

Geoffrey Lynn Price, The $C^{*}$-algebras generated by pairs of semigroups of isometries satisfying certain commutation relations $\ldots \ldots \ldots \ldots \ldots \ldots 315$

John Kurt Sauter, Jr., Isomorphisms among monodromy groups and

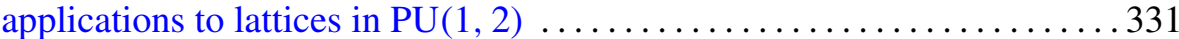

Shoji Yokura, A formula for Segre classes of singular projective varieties . . 385 